\title{
The influence of model structure on groundwater recharge rates in climate-change impact studies
}

\author{
Christian Moeck $^{1,2}$ • Philip Brunner ${ }^{1}$ Daniel Hunkeler ${ }^{1}$
}

Received: 15 August 2015 / Accepted: 10 January 2016 / Published online: 13 February 2016

(C) Springer-Verlag Berlin Heidelberg 2016

\begin{abstract}
Numerous modeling approaches are available to provide insight into the relationship between climate change and groundwater recharge. However, several aspects of how hydrological model choice and structure affect recharge predictions have not been fully explored, unlike the wellestablished variability of climate model chains - combination of global climate models (GCM) and regional climate models (RCM). Furthermore, the influence on predictions related to subsoil parameterization and the variability of observation data employed during calibration remain unclear. This paper compares and quantifies these different sources of uncertainty in a systematic way. The described numerical experiment is based on a heterogeneous two-dimensional reference model. Four simpler models were calibrated against the output of the reference model, and recharge predictions of both reference and simpler models were compared to evaluate the effect of model structure on climate-change impact studies. The results highlight that model simplification leads to different recharge rates under climate change, especially under extreme conditions, although the different models performed similarly under historical climate conditions. Extreme weather conditions lead to model bias in the predictions and therefore must be considered. Consequently, the chosen calibration strategy is
\end{abstract}

Electronic supplementary material The online version of this article (doi:10.1007/s10040-016-1367-1) contains supplementary material, which is available to authorized users.

Christian Moeck

christian.moeck@eawag.ch

1 University of Neuchâtel, Centre for Hydrogeology and Geothermics (CHYN), Neuchâtel, Switzerland

2 Present address: Eawag: Swiss Federal Institute of Aquatic Science and Technology, Dübendorf, Switzerland important and, if possible, the calibration data set should include climatic extremes in order to minimise model bias introduced by the calibration. The results strongly suggest that ensembles of climate projections should be coupled with ensembles of hydrogeological models to produce credible predictions of future recharge and with the associated uncertainties.

Keywords Groundwater recharge $\cdot$ Climate change $\cdot$ Model complexity $\cdot$ Uncertainty

\section{Introduction}

Evaluating the effect of climate change on water resources is essential for their sustainable management. Therefore, numerous climate impact studies have been carried out to provide insight into the relationship between climate change and water resources (e.g. Aeschbach-Hertig and Gleeson 2012; Goderniaux et al. 2009; Scibek and Allen 2006b; Green et al. 2011; Newcomer et al. 2014; Pulido-Velazquez et al. 2015; Rossman et al. 2014; Shamir et al. 2015; Toews and Allen 2009; Woldeamlak et al. 2007; Zhang et al. 2014 among others).

A frequent goal in climate-change impact studies is to quantify groundwater recharge. Groundwater recharge is one of the main drivers of hydrogeological systems (Green et al. 2011; Bakker et al. 2013) and a key parameter for sustainable water resource management (Kinzelbach et al. 2003). Currently, a variety of different models are used to estimate recharge in climate-change-impact studies. These models can be grouped into four general categories: (1) simple empirical relationships between precipitation and recharge (e.g. Owor et al. 2009; Serrat-Capdevila et al. 2007); (2) soil-water-balance models (e.g. HELP model, SMBM, Lumprem, EPIC-GRID 
soil model; Allen et al. 2004; Brouyere et al. 2004; Jyrkama and Sykes 2007; Mileham et al. 2008; Mileham et al. 2009; Scibek and Allen 2006a; Kurylyk and MacQuarrie 2013); (3) soil water balance models embedded within a coupled hydrological modeling framework that facilitates more realistic boundary conditions (e.g. FEFLOW and the Mike SHE twolayer water balance model; Stoll et al. 2011; van Roosmalen et al. 2009; (4) models based on the Richards' equation (e.g. HydroGepshere, ParFlow and HYDRUS; Ferguson and Maxwell 2010; Goderniaux et al. 2009, 2011 ; Leterme et al. 2012; Sulis et al. 2011, 2012).

An important question corresponds to how model choice affects a prediction. Cuthbert and Tindimugaya (2010) demonstrated that different groundwater recharge models gave similar long-term historic recharge rates but responded very differently to changes in precipitation intensity. Jiang et al. (2007) used six water balance models and identified differences in future recharge simulations. Hartmann et al. (2012) choose five different lumped models to incorporate model uncertainty for water availability simulations. The differences in the models had a strong impact on the ensemblesimulated discharge already occurring during the control period. Bastola et al. (2011) compared the uncertainty from model structure and parameter sets in a climate change study by using four conceptual rainfall-runoff models and two approaches to evaluate parameter uncertainty. They concluded that the role of the hydrological model uncertainty can be remarkably high. In more general terms, Bastola et al. (2011), Crosbie et al. (2011, Holman (2006) and Döll and Fiedler (2008) emphasized that the choice of the hydrogeological model will influence the outcome of climate-change impact studies.

Apart from the chosen model structure, additional sources of uncertainty exist. For example, in its simplest form, a Richards' equation type model such as HYDRUS can be employed with assumed homogenous subsoil properties. Alternatively, the variability of the hydrologic properties within the model domain can be considered by increasing the number of model parameters. As demonstrated in various studies (e.g. Schluter et al. 2012; Moeck et al. 2015), the degree to which variability of the subsoil is considered can have a profound impact on predictions. In addition to the model parameterization, the chosen calibration strategy is also important. Like for any other model, model parameters employed are typically determined through calibration. The amount of observation data and their variability within the calibration period influence the calibrated parameter values as demonstrated for rainfall-runoff models. For example, whether or not extreme values are present in the observation data set can have a profound impact on the prediction (Coron et al. 2012; Merz et al. 2011; Seiller et al. 2012; Vaze et al. 2010). Brigode et al. (2013) emphasized that the reliability of models for climate-change impact studies should be increased, particularly in the development of suitable model structures and calibration strategies that increase their model performance robustness. Although the effect of the calibration period is known for rainfall-runoff models it still remains unclear if groundwater recharge models are also affected.

Only a few studies exist which compare most of the aforementioned sources of uncertainty in climate-change impact studies (e.g. Teng et al. 2012; Crosbie et al. 2011; Kingston and Taylor 2010). Crosbie et al. (2011) compared the uncertainty in recharge prediction among five GCMs, three downscaling methods and four hydrological models. They found that the choice of the GCM gives rise to the largest uncertainty in future recharge estimates followed by the downscaling method. The choice of the hydrological models contributed least to the overall uncertainty. Although Crosbie et al. (2011) indicate general trends, all predictions are based on homogenous model parameterizations. The effects of the calibration strategy and observation period were not considered and the missing link between the mechanics of the model structure and the recharge under climate change was not established. This however, might be important due to the fact that the models were not always consistent in their predictions, even though they perform similarly for the calibration period. Why these discrepancies in model predictions occur still remains unclear; furthermore, little is known about whether the discrepancies in model results are stationary within climate change simulations or whether the results will change by considering different future simulation periods. Consequently, there is a lack of knowledge about the importance of the different types of uncertainty, although the aforementioned studies already indicate a few general trends.

Therefore, these four different sources of uncertainty were considered and compared - namely, the variability related to the climate model chains (GCMs-RCMs combinations), choice of hydrological models, and different parameterizations of models, as well as used observation data employed during model calibration in a systematic way. Predictions of how climate change affects recharge quantity and dynamics are fundamental for developing suitable water-resourcesmanagement practices. A solid understanding of how reliable these predictions are is indispensable.

This paper quantifies and compares all these different types of uncertainty using different model performance criteria. More specifically, the following questions are addressed:

1. How the choice of hydrological models influences predictions of recharge is systematically assessed.

2. How different parameterizations of models (e.g. homogenous vs. heterogeneous) affect predictions of recharge for different climate model chains is assessed.

3. The influence of used observation data employed during model calibration on model performance and predictions is analyzed. Specifically, models are calibrated using observation data covering average climatic conditions only, 
and the predictions based on calibrated models under extreme weather conditions are compared.

As future recharge rates are unknown, a complex twodimensional (2D) heterogeneous reference model is used as a proxy for real groundwater systems. This study refers to groundwater systems with minor head fluctuations. The study is based on a lysimeter facility (Zurich Reckenholz) from where the model geometry and dimensions of the 2D heterogeneous reference model was taken. Furthermore, soil properties, climate forcing functions and predicted changes under climate change were adopted from one lysimeter of the lysimeter facility. A semi-synthetic approach was chosen due to a variety of farming management practice such as cropping, fallow rotations and tillage at the lysimeter. These actions highly influence all observations required for the model calibration; to incorporate all these effects is beyond the scope of this study. Considering changing crop cover associated with irregular and often unknown cropping and harvesting cycles as well as tillage effects would certainly limit a systematic and robust comparison of different model complexities.

\section{Methods and modeling strategy}

Simpler models were calibrated against monthly groundwaterrecharge time series generated by the reference model, and used as a proxy for real systems. Monthly recharge values were chosen for the calibration. As emphasized by Kresic (2006) monthly values in the model calibration enable one to obtain reliable simulations of seasonal effects, which is very important for long-term predictions on climate change. This choice is widely applied because it allows for relating recharge values to stream discharge (Seneviratne et al. 2012). For each of the four aforementioned model categories - simple empirical relationships between precipitation and recharge, soilwater balance and semi-mechanistic models, as well as models based on the Richards' equation —one recharge model was chosen. Calibration was carried out using the automatic parameter estimation software PEST (Doherty 2011) for soil and vegetation parameters for each simplified recharge modelTable S1 of the electronic supplementary material (ESM).

Best-estimate model parameters were used to systematically evaluate the model performance under historical and future climate conditions. All recharge models were run for 30 years of daily simulations for four time periods - historic conditions and three future time periods: mid-point 2035 (2021-2050), midpoint 2060 (2045-2074) and mid-point 2085 (2070-2099). In order to estimate uncertainty under future climatic conditions, different GCM-RCM combinations were applied for the three future time periods. Finally, three different calibration periods, containing recharge values from an average year (2010), from a sequence of a wet and a dry year (2002/2003) and from the
2004-2009 period (longer time series with average to slightly dry years), were used to evaluate whether simpler models show less predictive model bias when extreme conditions and longer time series of observation are included in the calibration.

\section{Reference model for recharge estimation}

\section{Numerical model}

The reference model was constructed using the fully coupled physically based model HydroGeoSphere (HGS; Therrien et al. 2010). A control volume finite element approach is used to solve Richards' equation describing 3D variably saturated subsurface flow. The soil hydraulic model follows the Van Genuchten (1980) formulation. Precipitation is partitioned into runoff, infiltration and evapotranspiration (ET), which is calculated following Kristensen and Jensen (1975) and is a function of potential evapotranspiration, soil moisture, evaporation depth, root depth, and leaf area index (LAI; Brunner and Simmons 2012). Infiltration occurs when precipitation exceeds evaporation and interception storage; a more detailed description of the model and all its components can be found in Therrien et al. (2010) and in the ESM.

\section{Model setup}

The forcing functions, soil properties (hydraulic conductivity range, van Genuchten parameters and porosity) and model dimensions were based on the Zürich Reckenholz lysimeter. The lysimeter has a surface area of $1 \mathrm{~m}^{2}$ and depth of $150 \mathrm{~cm}$. The steel cylinders are filled with undisturbed sandy soil. No overland flow can occur due to a steel edge surrounding the top of the lysimeter. The measured lysimeter discharge at the bottom of the lysimeter is used to represent groundwater recharge.

Based on the geometry of the lysimeter, a vertical 2D heterogeneous reference model was created with $150 \mathrm{~cm}$ depth in the z-direction, $100 \mathrm{~cm}$ in the $\mathrm{x}$-direction and $5 \mathrm{~cm}$ discretization horizontally and vertically (Fig. 1). This fine discretization was necessary to obtain a numerical solution with reasonable accuracy (Vogel and Ippisch 2008).

Soil properties from different depths were used to create hydraulic conductivities based on Rosetta, a program for pedo-transfer functions (Schaap et al. 2001). The hydraulic conductivities at different depths were subsequently used to create a variogram for the stochastic field generator to generate the hydraulic conductivity field. Hydraulic conductivity was distributed within the model domain using the program Fieldgen (Doherty 2011), a 2D stochastic field generator, while field generation was undertaken using the Gaussian sequential simulation principle.

To apply the Richards' equation, van Genuchten parameters were employed in addition to the generated hydraulic conductivity. A related challenge to this model 
Fig. 1 Soil structure for the heterogeneous synthetic $2 \mathrm{D}$ reference model with $\log$ saturated hydraulic conductivity distribution from -13 to -7.5 $\left[\mathrm{m} \mathrm{s}^{-1}\right]$ and $150 \mathrm{~cm}$ depth in the $z$ direction, $100 \mathrm{~cm}$ in the $x$ direction and 5-cm discretization horizontally and vertically. A specified flux boundary was applied on the top of the column and a fixed head boundary at the bottom with pressure $p=0$. The actual ET rate is a function of potential ET, $L E A F$, (water content), root depth and evaporation depth

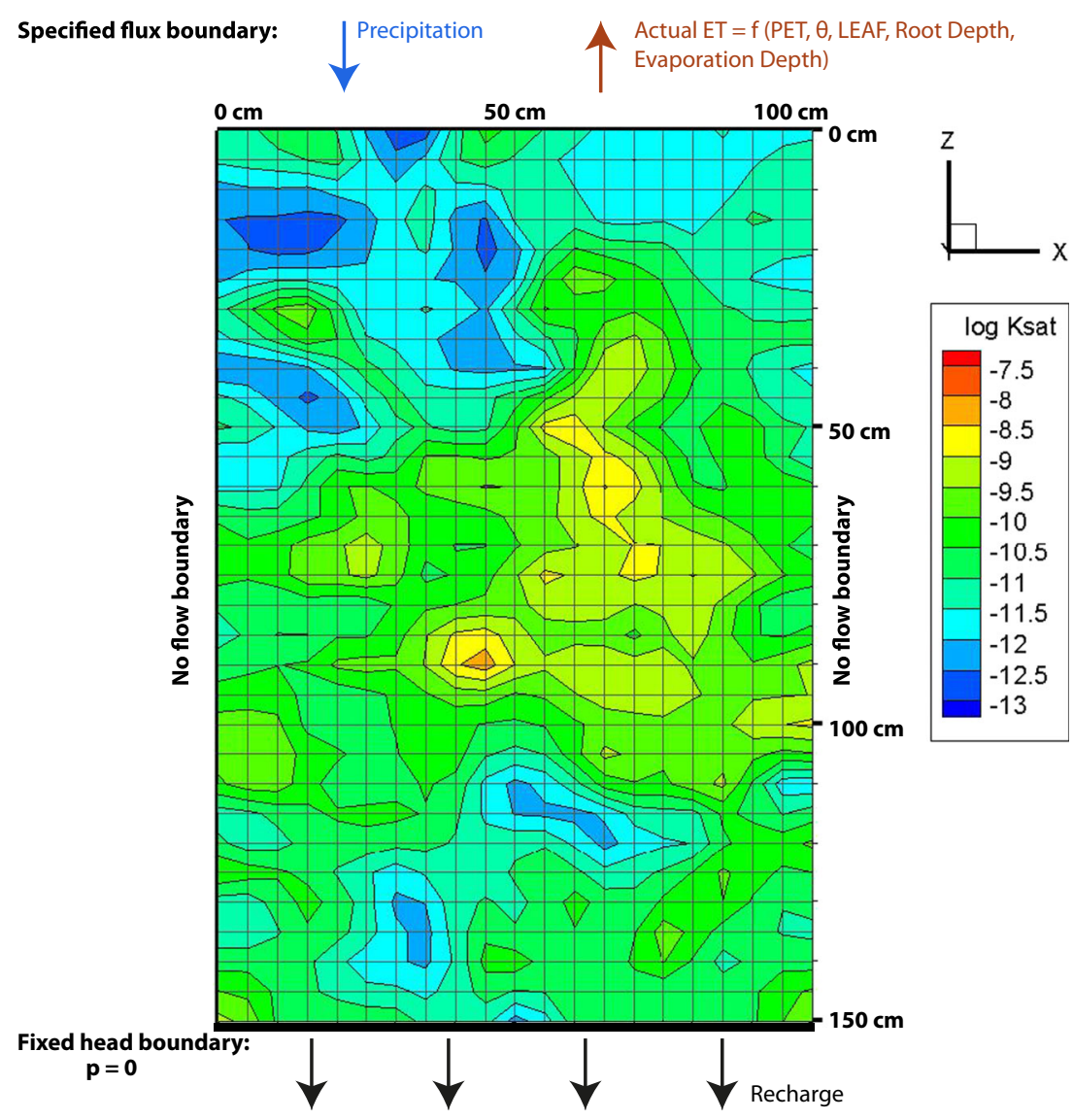

parameterisation is to avoid unrealistic relationships between randomly generated hydraulic conductivities and the van Genuchten parameters. Therefore, van Genuchten parameters were assigned to each mesh node based on the relationship between hydraulic conductivity and the van Genuchten parameters alpha, beta and residual water content (Carsel and Parrish 1988). The variance associated with this relationship was taken into account. This approach leads to a more realistic representation of natural soils (Fig. S1 of the ESM). In addition, porosity was distributed and adapted from a standard normal Gaussian distribution for the entire soil column and ranged from 0.33 to 0.38 , similar to measured values from the lysimeter soil samples; furthermore, in order to represent spatial heterogeneity in a more robust way, 130 stochastic realizations of the soil parameters were carried out. The hydraulic conductivities from different depths were used to create a variogram. Based on these observations, an exponential variogram with a range of $0.5 \mathrm{~m}$ and a sill of 0.29 was obtained; however, not only a sill of 0.29 was applied, also different sill values were used to consider moderate and comparatively stronger heterogeneity in order to cover a wider range of different possible soil structures. A sill of 0.29 was used for 100 realizations and a value of 1 for the remaining 30 .
Preliminary consideration of heterogeneity shows, however, that for the considered specific soil type with the associated stochastic realisations, recharge is dominated by precipitation patterns and not by the adopted soil structure. Therefore, a full stochastic analysis was not required, which reduced the computational demand considerably; however, in soils with dominant macro components or different clay content, it might be different as demonstrated by Kim and Jackson (2012); Lorenz and Delin (2007) and Wohling et al. (2012). Petheram et al. (2002) point out that soil structure becomes more important for higher clay content soils compared to sandy soils. The adopted soil structure in this study can be characterised rather as a sandy soil than a clay or loam.

Model parameters such as root zone and LAI were added to the model to simulate the presence of a constant grass cover. Interception, which involves retention of a certain amount of precipitation, was further included in the model setup. Altogether, 3,014 parameter values describe the 2D heterogeneous model domain-applied model parameters can be found in Table S2 of the ESM.

A specified flux boundary was applied on the top of the column with daily values for potential ET and precipitation. Although daily values were used for the climatic forcing functions, an adaptive time stepping was used for the simulations which ensure that the model is running on sub-daily time steps 
when a change in, e.g., saturation occurs. A fixed head boundary was used at the bottom. This chosen boundary, based on the lysimeter setup, might affect the timing of recharge; however, the absolute rates are not affected due to a relatively small extinction depth and evaporation for the considered specific soil with grass cover (Shah et al. 2007). No-flow boundary conditions were applied to the remaining borders of the soil column.

Daily time series of actual precipitation and air temperature were used over a period from 01.01.1982 to 31.12.2011 as model inputs (Fig. S2 of the ESM). Snow accumulation can be neglected due to the temperature pattern at the study area. The time series were measured at the MeteoSwiss weather station in Zurich-Reckenholz, Switzerland, situated at the lysimeter facility. Potential evapotranspiration was calculated using the Penman-Monteith equation after Allen et al. (2005). The average annual precipitation and potential ET is 900 and $550 \mathrm{~mm} /$ year, respectively.

\section{Simplified models for recharge estimation}

In this section, the four simplified models are described and a schematic summary of the model structures is given in Fig. S3 of the ESM.

\section{- Homogeneous one-dimensional (1D) model (1d1L)}

As a first simplified model (referred to as $1 \mathrm{~d} 1 \mathrm{~L}$ ) a HGS model was used but with a homogeneous model parameter discretization, while maintaining the same conceptualization of the underlying physical processes described for the reference model.

\section{- $\quad$ Lumped parameter bucket model (Lumprem)}

The second model was a lumped parameter "bucket" model named Lumprem, which was successfully used in a model simplification study by Watson et al. (2013). The model provides a basic representation of the unsaturated zone, including matrix and macropore recharge. Matrix and macropore recharge are activated after specified delay times. Lumprem calculates the actual evapotranspiration taking soil moisture storage and plant parameters into account. Water is lost from the bucket as unsaturated vertical flow (Fig. S3 of the ESM). The recharge rate depends on the soil moisture quantity in the bucket. The soil moisture quantity also controls the hydraulic conductivity. A decreasing soil moisture store lowers the hydraulic conductivity, following the concept of the water retention curve.

\section{- Soil-water-balance model (Finch)}

In this soil-water-balance model (referred to as Finch) direct recharge is calculated using a simple daily water balance.
Recharge occurs when the soil moisture content exceeds the field capacity (von Freyberg et al. 2015). Interception and root water uptake was included. Water uptake from plant roots occurs at the given rate as long as there is no water stress. The root zone for the Finch model was divided into four layers (Fig. S3 of the ESM) following the standard approach of Finch (1998). For a more comprehensive description of the model, see Finch (2001), Finch (1998).

\section{- Soil-water-balance model (SWB)}

This soil-water-balance model (referred to as SWB) depends only on one soil-water storage parameter. Recharge can only occur if the threshold of this parameter is reached. The amount of water surpassing the threshold is equal to recharge (see Fig. S3 of the ESM). Changes in storage result from subtraction of actual evapotranspiration from precipitation as well as storage changes from the previous day. A soil function, which depends on the chosen soil storage parameter, reduces the potential for actual evapotranspiration (Richter and Lillich 1975).

\section{Model performance evaluation}

Different performance criteria are applied in order to quantify the effect of model simplification and different model calibration approaches on recharge predictions under climate change. The application of such multiple performance criteria is generally recommended because a single criterion evaluates only specific aspects of model performance (e.g. Krause et al. 2005). Bennett et al. (2013) mentioned that model performance criteria which are applicable for one specific model application may not be sufficient for another. The following performance measures were introduced - a modified modelscenario ratio (MSR; Droogers et al. 2008), the Nash Sutcliffe model efficiency coefficient (Nash and Sutcliffe 1970) and percent of bias (PBIAS; Gupta et al. 1999).

The MSR indicates to what extent the impact of a scenario contributes to predictions compared to model simplification. The MSR has a range from 1 to $-\infty$, where 1 indicates that model simplification does not affect the results and recharge changes are a function of the future forcing functions only. Values less than 0 indicate that model simplification is the dominant factor for changes in recharge rates rather than the scenario. Like the MSR, the NSE also provides values between 1 and $-\infty$, where 1 indicates a perfect match and model simplification does not affect change in future recharge rates. PBIAS provides a measure of over- or underestimation for each scenario. An optimal value is $0 \%$, while a positive value indicates an underestimation and a negative value an overestimation of yearly recharge rates. A more detailed description for all applied indicators can be found in the ESM. 


\section{Climate change scenarios}

To simulate future climate conditions, a total of ten GCMRCM model chains (Fig. 2 and Table S3 of the ESM) for the A1B emission scenario were used (CH2011 2011). Thirty time series were created comprising ten model chains for three climate change periods, in order to estimate uncertainty under possible future climatic conditions. The scenarios were derived directly from the output of individual GCM-RCM model chains by means of the statistical downscaling technique to the MeteoSwiss monitoring network, with an inverse distance weighting interpolation (Bosshard et al. 2011). Bosshard et al. (2011) developed an extension of the simple delta change method that scales observational time series by a climate change signal extracted from climate model output. Thirtyyear mean annual cycles of temperature and precipitation were represented by a superposition of harmonics. This method ameliorates the effects of natural variability on artificial fluctuations in the annual cycle - more details about the downscaling method are given in Bosshard et al. 2011 and CH2011 2011. The obtained model chains provide a daily time series of delta change factors for precipitation and temperature relative to the reference period $1980-2009$ for three time periods: 2035 (2021-2050), 2060 (2045-2074) and 2085 (2070 2099). Changes in temperature lead directly to changes in ET.

In the following analysis, all applied recharge models were run for 30 years of daily simulations for each time period. Note that using only one emission scenario and one downscaling method constrained the uncertainty analysis (van Vuuren et al. 2011). Using more emission scenarios would certainly increase the uncertainty related to the GCM-RCM combinations; however, the used delta change method is still one of the most used approaches in hydrological impact studies (Goderniaux et al. 2015); Teutschbein and Seibert 2012) and the choice of using one emission scenario is mainly based on several restrictions of the downscaling method to station scale. The restrictions are methodological aspects (some driven model chains can produce an overshooting of climate change signals at some locations; see Bosshard et al. 2011 for details) and reduced data availability on a daily scale (CH2011 2011), as well as length of the simulation period (CH2011 2011).
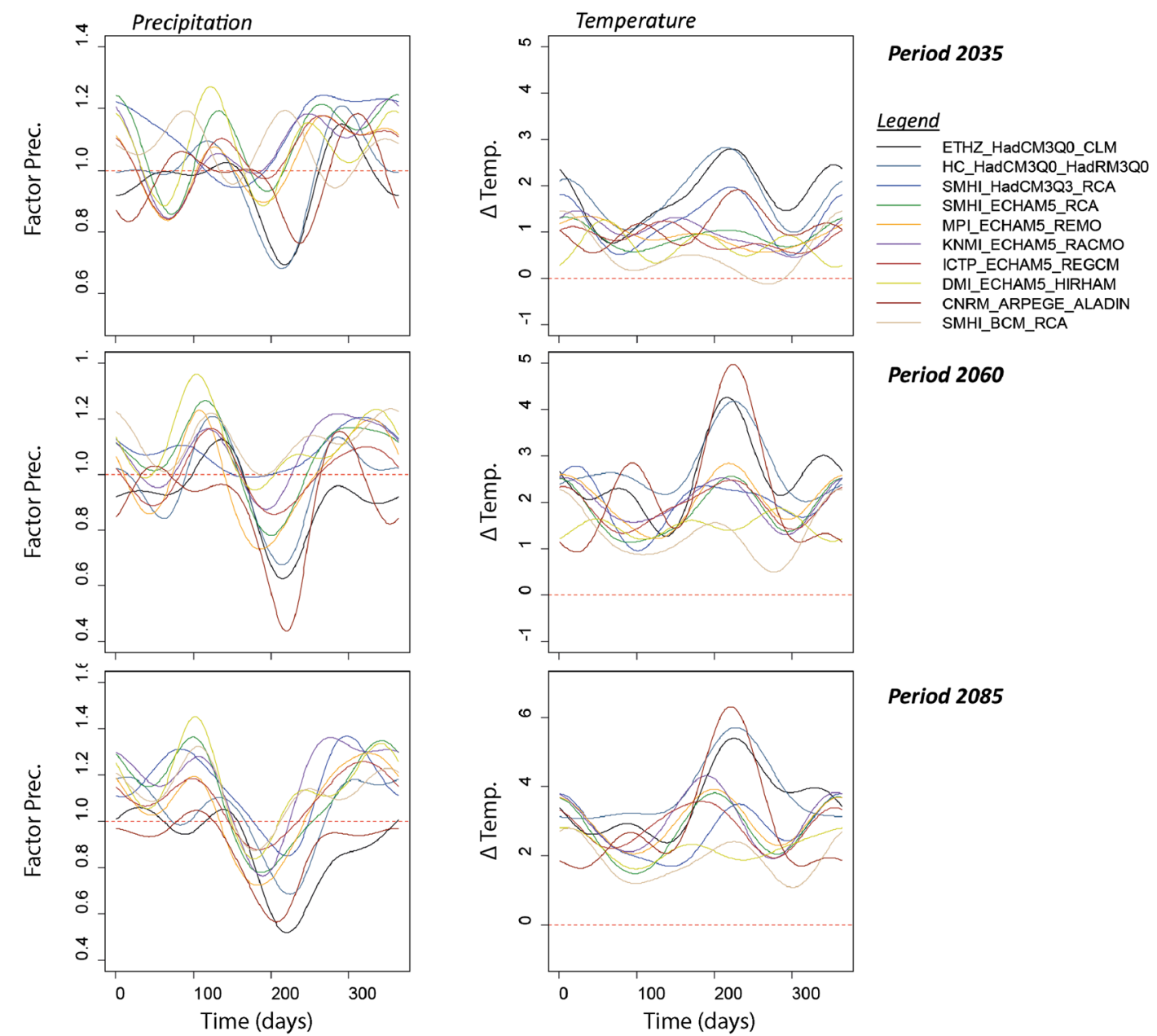

Period 2060

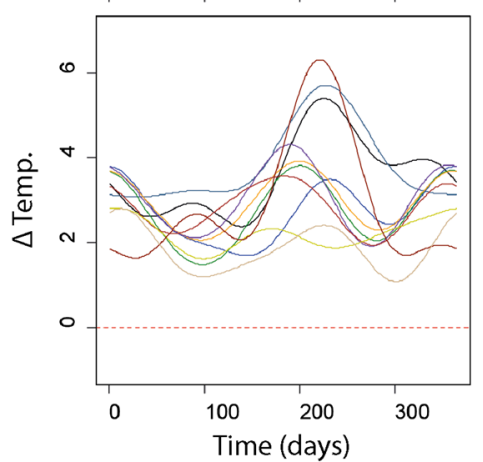

Period 2085

Fig. 2 Daily climatic change factors (delta-change approach) for each climate model chain for scenario A1B. The left column shows factor changes in daily precipitation, the right column shows mean daily delta temperature changes for the MeteoSwiss weather station in Zurich-Reckenholz 


\section{Results and discussion}

In the following section, results of the model calibration of the simpler models against the reference recharge are shown. The best-estimate model parameters were used to systematically evaluate the model performance under historical and future conditions. A comparison between three calibration periods was carried out, in order to evaluate if simpler models show a better model performance if different calibration data sets were applied and, lastly, the relationship between model structure, calibration data set and model performance for climatechange impact studies is addressed.

\section{Calibration under average climatic conditions and validation}

For the calibration period 2010, the simpler calibrated recharge models reproduced the monthly and cumulative reference recharge surprisingly well, despite considerably different model structures (Fig. 3a,b as well as Table S4 of the ESM).However, sharp rises of recharge after strong precipitation events appear for the SWB and Finch model, while the recharge pattern is smoother for the other models. The different behavior can be directly related to the conceptual model complexity, discussed later. For the validation period 20112013, including a year with a long dry spell in spring 2011 (Staudinger et al. 2015), differences in recharge occur for all simpler models, especially for the SWB and Finch model.

Simulating the historical recharge with the reference model for a 30-year period leads to a mean annual value of $543 \mathrm{~mm} /$ year which is very similar to simulated mean annual recharge of $588 \mathrm{~mm} /$ year for a study area in northern Switzerland, east of the city of Zurich (Stoll et al. 2011). In addition, similar values are also found in both studies for actual evapotranspiration. Although recharge differences increase for the validation period between the reference model and the simplified models, the simple models perform quite well for the historical climate conditions (Fig. 3c). This 30-year simulation of historical recharge shows only small variability among the different models. The SWB model underestimates $(-10 \%)$, whereas the Finch model overestimates $(+7.5 \%)$ the total recharge rate. Also, the $1 \mathrm{~d} 1 \mathrm{~L}$ and Lumprem models respectively over- and underestimate the predicted value from the reference model, although by less than $2 \%$.

\section{Model performance for future climate conditions}

Simulations of recharge for the period 2035 show a large variability in the results (Fig. 4). The mean groundwater recharge increases by $4.2 \%(+22.8 \mathrm{~mm})$ for the $2 \mathrm{D}$ reference model considering all 10 climate model chains relative to the historical modelled reference period 1982-2011. However, due to the variability among the different climate model chains, a range of mean change of groundwater recharge between $-4.3 \%(-23.3 \mathrm{~mm})$ and $+14.4 \%(+78.1 \mathrm{~mm})$ was simulated. Similar ranges can also be observed for all other groundwater recharge models (Table 1). It is interesting to note that models with increasing simplification tend to underestimate changes in recharge compared to the more complex reference 2D model. Mean recharge as well as the lower (minimum) and upper bound (maximum) of recharge decrease with increasing model simplification.

In Fig. 5 deviations of future recharge (2035 period) from the baseline scenario are shown for all models and all climate model chains. The variability is larger among climate model chains than among recharge models. For different climate model chains, the mean deviation of each model spreads over a range of $130 \mathrm{~mm} / \mathrm{year}$, while for a given climate model chain, all recharge models fall within a range of $30 \mathrm{~mm} / \mathrm{year}$ only. The model $1 \mathrm{~d} 1 \mathrm{~L}$ shows recharge values close to
Fig. 3 a 2D simulated monthly reference recharge (red dashed line) and fitted recharge for $1 \mathrm{~d} 1 \mathrm{~L}$ (orange line), Lumprem (blue line), Finch (green line) and SWB model (purple line) for the 2010 and 2013 period. The 2D

reference recharge from the year 2010 was used for the calibration of the simplified models. The recharge values from years 2011 2013 were used for the validation. b Monthly recharge for the year calibration year 2010 and validation period 2011-2013 and c cumulative daily recharge between 1982-2013
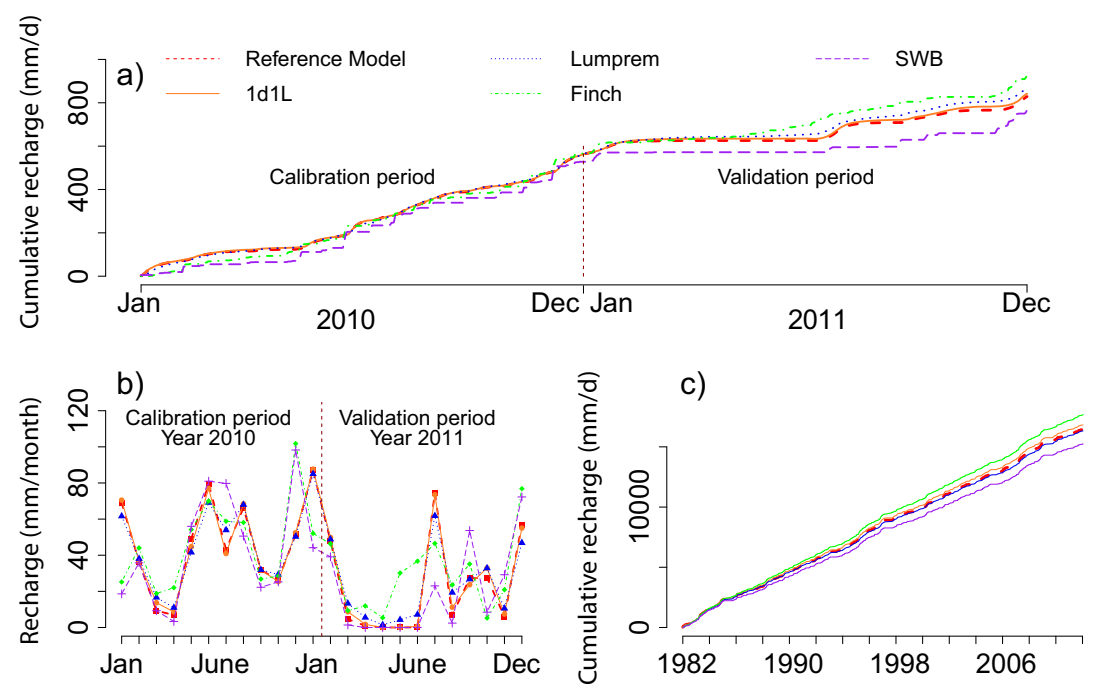

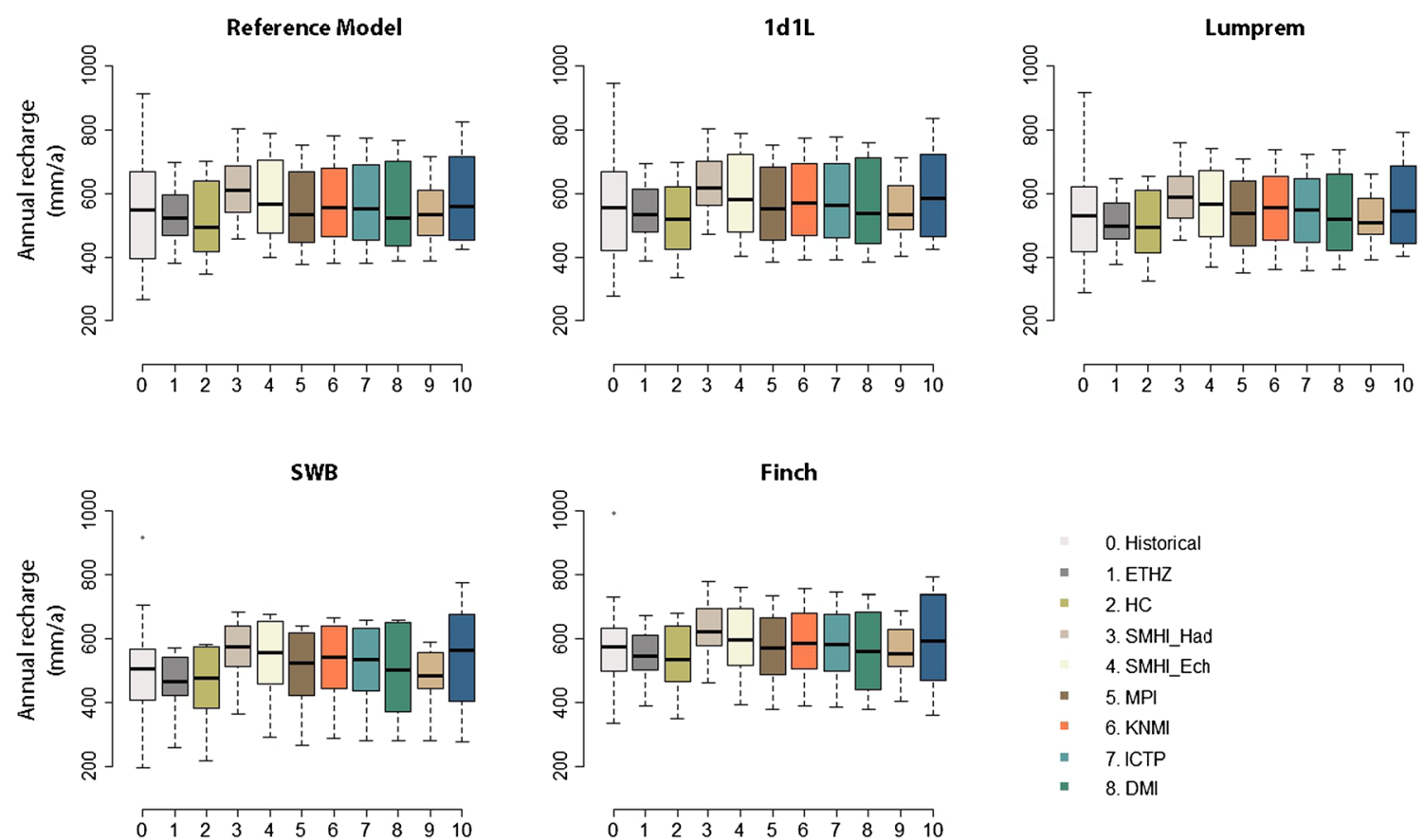

Fig. 4 Boxplot of 30-year historical recharge and for 10 climate model chains for the period 2035 based on delta change factors. Color filled boxes show the upper and lower quartile with the mean value as a black

line within the boxes. The whiskers, vertical lines emanating from each box, indicate values outside the upper and lower quartile

predictions from the reference 2D model. The Finch and SWB models perform differently. Based on the Finch model, more climate model chains would predict a decrease in recharge, whereas the reference model indicates an increase. An identical pattern between all recharge models for each climate model chain can be observed.

\section{Effect of extreme climatic conditions for model performance and calibration}

In section 'Model performance for future climate conditions', it was observed that an identical pattern between all models for each climate model chain exists. Here, the drivers for the observed model bias were identified by using the MSR for each year. For most years, the MSR values are greater than 0.9 for each recharge model, meaning that model simplification does not have a dominant effect and changes in recharge for future climate conditions are only a function of the scenario (Fig. 6); however, for each model, some outliers appear. These outliers correspond to weather conditions with distinctly different precipitation amounts and distributions, as well as temperature values. For instance, the drought year 2003 offset by the delta change values corresponds to the lowest value for each recharge model and climate model chain. The corresponding values for the outliers are approximately 0.85 (1d1L), 0.65 (Lumprem), 0.4 (Finch) to 0 (SWB). This pattern shows the sensitivity of the models to extreme climatic conditions and can be directly related to the conceptual model complexity, discussed in the next section. The SWB and Finch models give similar results to the physically based models for those years with average temperature ranges and precipitation distribution; for extremes, however, they simulated different recharge rates. Although model simplification does not have a dominant effect for most years, the model sensitivity to climatic extremes can, however, become increasingly important due to a higher probability, frequency and duration of extremes in future periods (Schar and Jendritzky 2004). Calculating the NSE and PBIAS for each climate model chain, a similar order of model performance following the degree of simplification among the different models can be observed as well (Table S5 of the ESM).

The lowest values for NSE and highest values of PBIAS can be found for climate model chains with the strongest

Table 1 Percentage changes with respect to the historic condition for the scenario period 2035 (2021-2050) in groundwater recharge rates due to the variability between the different climate model chains and different groundwater recharge models

\begin{tabular}{lcclc}
\hline Model & Median (\%) & Mean (\%) & Min (\%) & Max (\%) \\
\hline 2D & 4.2 & 4.2 & -4.3 & 14.4 \\
1d1L & 3.1 & 3.4 & -5.6 & 14.0 \\
Lumprem & 1.1 & 1.6 & -6.3 & 11.6 \\
Finch & -1.7 & -0.9 & -7.7 & 8.0 \\
SWB & 0.9 & 1.4 & -9.6 & 13.5 \\
\hline
\end{tabular}




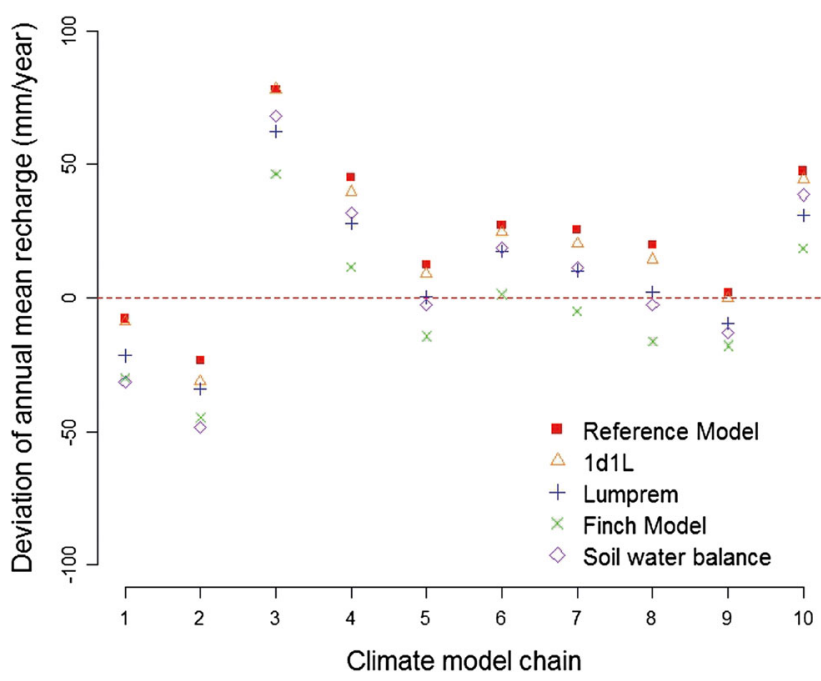

Fig. 5 Deviations between mean annual recharge from the historical baseline and for the period 2035 time slot for ten model chains

increase in temperature and decrease in precipitation (e.g. Table S5 of the ESM for the ETHZ_HadCM3Q0_CLM climate model chain). For future time periods (2060 and 2085), where the increase in temperature and change in precipitation distribution are greater than in 2035, the model performance for some models decreases.

Taking the climate change model chain ETHZ_HadCM3Q0_CLM as an example, it can be observed that over the complete time series (periods 2035-2085), the $1 \mathrm{~d} 1 \mathrm{~L}$ model shows only a small change in model performance (Fig. 7). Here, the NSE values are close to 1, whereas for all other recharge models, a decrease throughout the different climate model periods can be observed.

The decline in NSE follows the degree of simplification, and thus the SWB model shows the largest decrease up to a value of -2.5 . Similar observations can be made using PBIAS, where the percentage of bias increases with increasing time period. The $1 \mathrm{~d} 1 \mathrm{~L}$ and Lumprem model drift only slightly, whereas Finch, followed by SWB, shows a drastic change, indicating that the discrepancies between the models are not stationary within climate change simulations.

The monthly differences between the modelled reference 2D model recharge and the simplified models indicate that an underestimation occurs in spring and summer, whereas a small overestimation can be observed during autumn and winter (Fig. S4 of the ESM). This seasonal trend is stable over each time period for each simplified model and can be directly related to the conceptual model complexity discussed in the next section.

The relationship between predictive model bias and the calibration data set was quantified in order to evaluate whether simpler models show less predictive model bias for actual and future time periods when extreme conditions and longer time series of observation are included in the calibration. In addition to the year 2010 (average year), the years 2002/2003 (wet/ dry year) and a time series (year 2004-2009) were chosen as calibration periods. In Fig. 8, a comparison between the obtained MSR under the different calibration periods is shown. During the calibration period 2002/2003 an improved performance of the Finch model, especially for the outliers, can be observed. This is a direct consequence of including extreme
Fig. 6 Model scenario ratio (MSR) for the $1 d 1 L$, Lumprem, Finch and $S W B$ model for each climate model chain. Color-filled boxes show the upper and lower quartile with the mean value as a black line within the boxes. The whiskers, vertical lines emanating from each box, indicate values outside the upper and lower quartile. Points outside the whiskers show outliers for recharge estimations which corresponds to weather conditions with distinctly different precipitation amounts and distributions, as well as temperature values
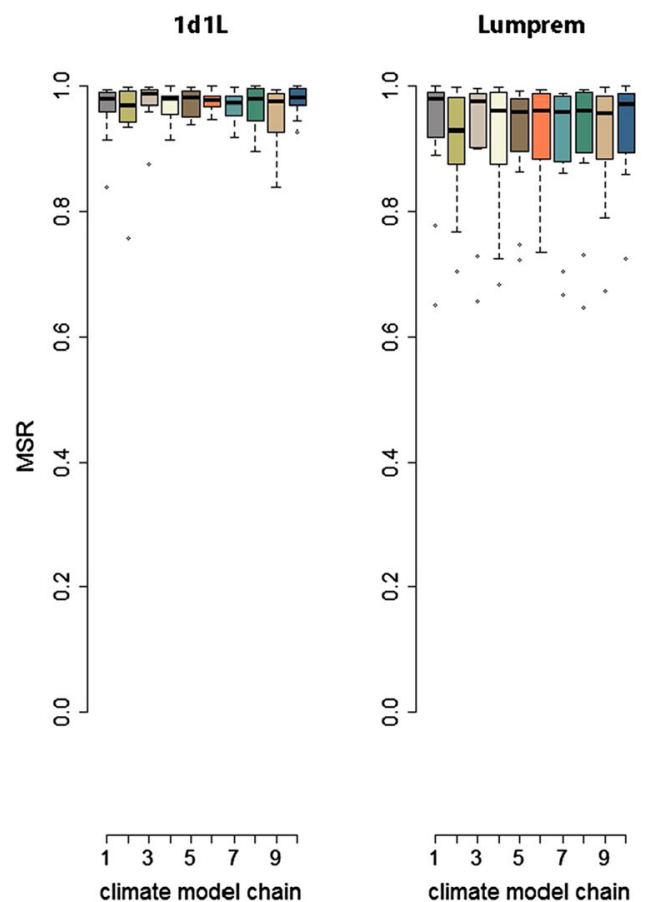

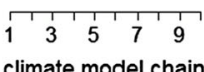

climate model chain
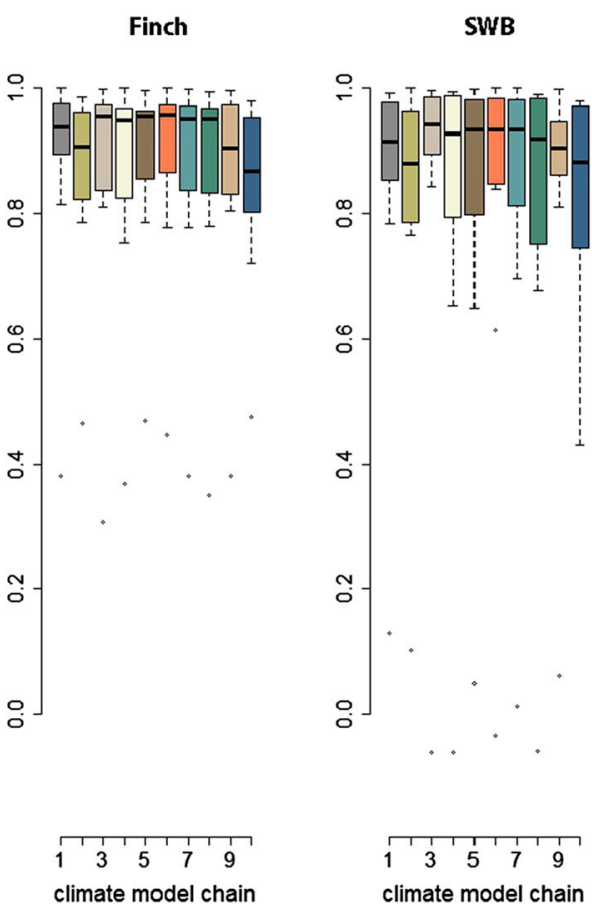

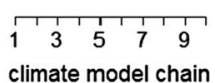


Fig. 7 Variations of a NSECoefficient and $\mathbf{b}$ PBIAS for different groundwater recharge models. ETHZ_HadCM3Q0 CLM climate model chain is used for the periods 2035, 2060 and 2085

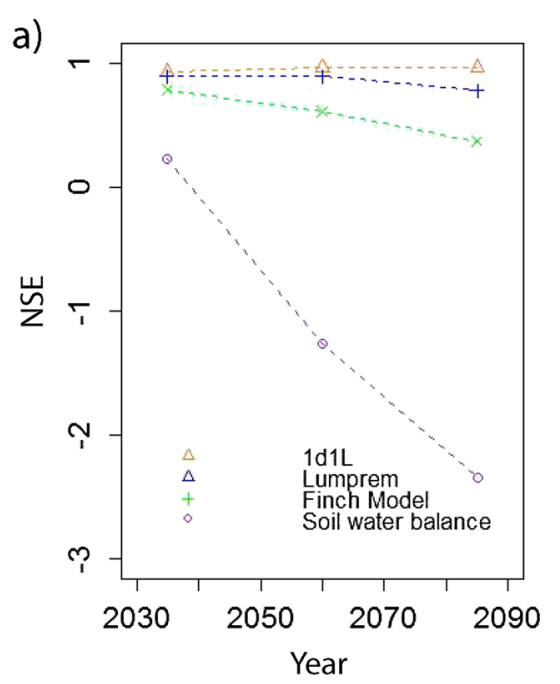

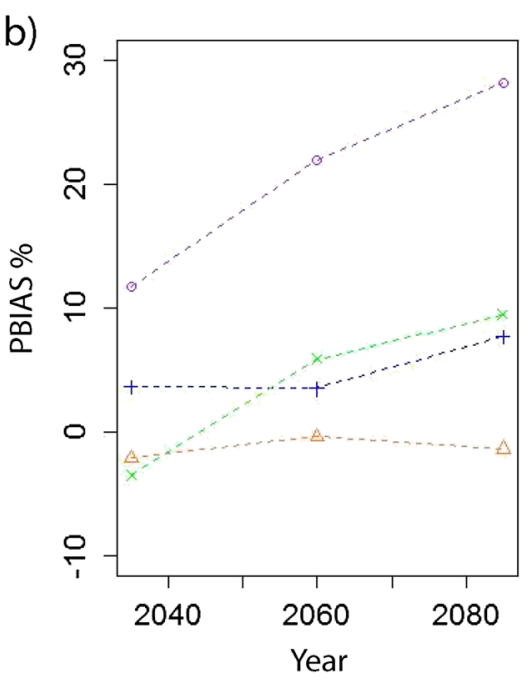

years in the calibration. Small changes for the $1 \mathrm{~d} 1 \mathrm{~L}$ and Lumprem models can be observed, whereas the SWB model with the inflexible model structure shows no change in MSR. Similar improvements can be found if the calibration period 2004-2009 is used. A longer time series in the calibration period increases the model performance for all models, with exception of the SWB model, which shows no better performance. The differences between the calibration period 2002/ 2003 and 2004-2009 are marginal, but slightly better for the latter case. Similar results can be observed for the MSR (mean), NSE and PBIAS (Table S6 of the ESM)-for instance, for the climate model chain CNRM APRPEGE_ALADIN (CNMR), the NSE increases from 0.49 to $0 . \overline{7}$.

\section{Relation between model simplification and model performance}

Changes in predicted groundwater recharge depend strongly on the degree of model simplification, and thus an important source of uncertainty is structural complexity. The interrelationships between model parameters and recharge for the empirical water balance models such as the Finch and SWB models, are based on a time series of observations and lead to an averaging effect. The extremes of historical climate conditions like extreme summer temperatures and precipitation events are smoothed out. This is why all simplified groundwater recharge models perform well for historical years with average temperature ranges and precipitation amounts but performance is different for extremes. These observations are in line with the study of Sorensen et al. (2014). They show a generally good agreement between simulated and observed soil moisture content for four soil-water-balance models but significant differences occur under extreme periods and in the seasonal patterns. Due to predicted distinctly different climate conditions with an increasing frequency of extremes, the smoothing effect becomes increasingly important.

From a mechanistic point of view, an important detail for recharge differences under extremes is related to ET processes. The effect of rapid infiltration in the reference model, often associated with strong summer precipitation events, cannot be simulated by the simplified models and leads to a general underestimation of the modelled reference recharge during the summer. In contrast, the overestimation during the winter shows that the simplified models simulate more recharge than the reference model, which indicates that the calibrated model parameter sets from the simplified models take a surrogate role to compensate the misfit during the summer. Satisfactory results can still be obtained for annual recharge but the errors between reference and simplified recharge on seasonal patterns are larger, which is also observed in a model comparison study of Ghasemizade et al. (2015) These results clearly show the advantages of using a $2 \mathrm{D}$ complex model compared to simple 1D model. It is, however, possible to reduce the averaging effect for the simple empirical models by choosing a calibration data set that includes climatic extremes or a long time period as demonstrated in this study and for instance by Coron et al. (2012) and Seiller et al. (2012) for rainfall-runoff models.

\section{Summary and conclusions}

A solid understanding of how reliable predictions associated with different kinds of uncertainty under climate change is indispensable. Therefore, a range of numerical experiments were established to understand the link between the different sources of uncertainties in climate change studies. The majority of previous studies did not consider uncertainty of the hydrogeological model conceptualization and only a few exceptions include a multi-model approach. Although these exceptions indicate 
Fig. 8 Comparison between the obtained MSR for each simplified model during the calibration period 2010 (brown color), 2002/2003 (light-blue color) and 2004-2009 (green color). Results for three model chains are shown, where an improved performance of the Finch model under the calibration period 2002/2003 and 2004-2009 can be observed, especially for the outliers that correspond to weather conditions with distinctly different precipitation amounts and distributions, as well as temperature values. Only small changes for the $1 \mathrm{~d} 1 \mathrm{~L}$ and Lumprem models can be observed, whereas the SWB model with the inflexible model structure shows no change in MSR. Color-filled boxes show the upper and lower quartile with the mean value as a black line within the boxes. The whiskers, vertical lines emanating from each box, indicate values outside the upper and lower quartile. Points outside the whiskers (small empty circles) show outliers for recharge estimations
$1 \mathrm{~d} 1 \mathrm{~L}$

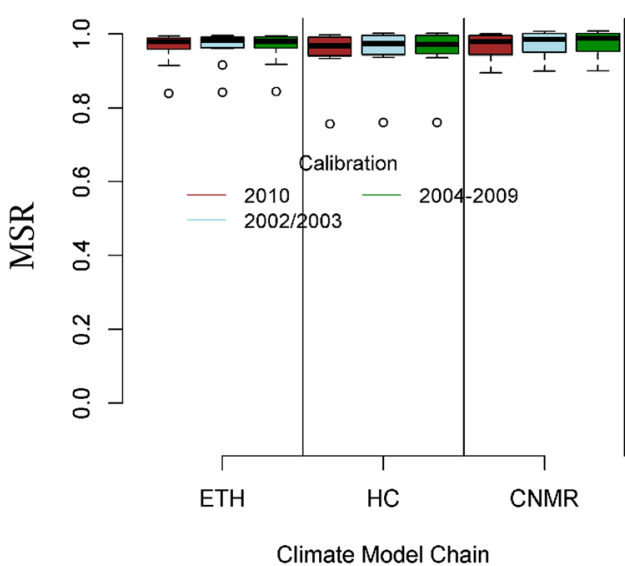

Finch

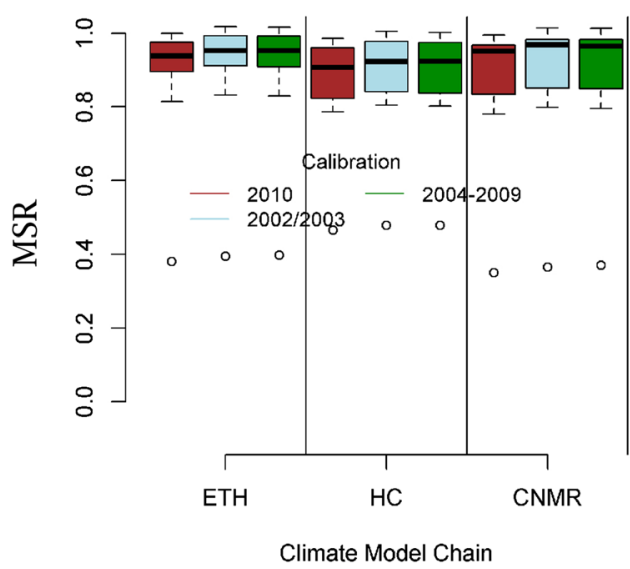

Lumprem

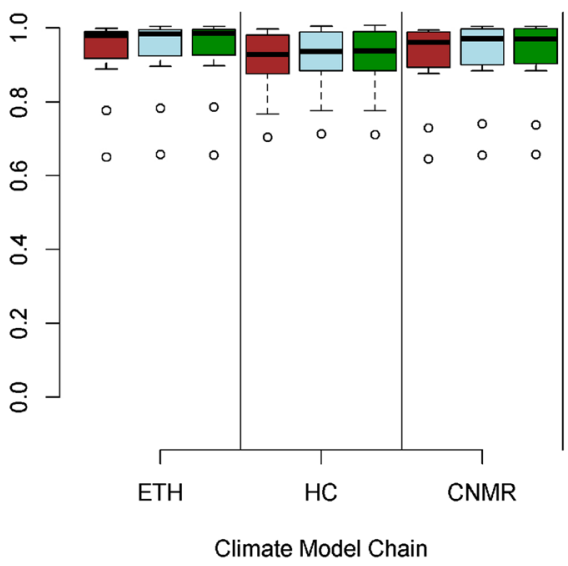

SWB

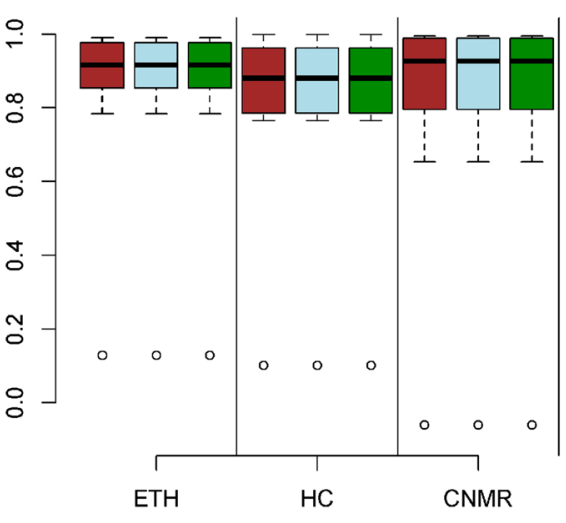

Climate Model Chain general trends, all predictions are based on homogenous model parameterization. The effects of the calibration strategy and observation period were not considered, and the missing link between the mechanics of the model structure and the recharge under climate change has not been yet established.

In the presented numerical experiment, a heterogeneous 2D reference model was generated based on a classical soil type to simulate historical and future groundwater recharge rates based on predicted future climatic forcing functions. Simpler models were calibrated against the modelled output of the reference model, and recharge predictions of both reference and simpler models were compared to evaluate the effect of model simplification for climate-change impact studies.

It was demonstrated that model simplification leads to different recharge rates under climate change. In addition, it was shown that the 1D homogenous physically based model best reproduces the reference recharge from the $2 \mathrm{D}$ heterogeneous model. The effect of variability in the hydrologic properties such as homogenous versus heterogeneous model parameterization has only a minor influence on recharge predictions in this specific case. However, it might be different in soils with dominant macro components or different clay content. The soil-waterbalance models perform differently and relatively poorly compared to the physically based and lumped models, especially under extreme conditions. In this numerical experiment, large differences in the predictions between a variety of models can be observed and are expected to occur for a wide range of soil types; furthermore it is expected that the differences become larger in reality due to higher degree of complexity.

The applied model performance indicators suggest, however, that model simplification is not the controlling factor for recharge differences under future climatic forcing functions. Recharge changes for future periods are mainly a function of the climate scenario, but more extreme weather conditions lead to model bias in the predictions and must be considered, especially due to the fact that discrepancies in model results are not stationary within climate change simulations.

Due to the influence of more extreme weather conditions, the chosen calibration strategy is also important. If possible, the calibration data set should include climatic extremes or a longer time series with a high variability to minimise the model bias induced by the calibration. Note that daily climatic 
forcing functions were used but it is expected that the differences between the models become larger in reality due to possible higher precipitation-event intensity on sub-daily scales.

The scientific community has emphasized the need to use outputs from a range of GCMs or RCMs to recognize the importance of climate model uncertainty (e.g. Goderniaux et al. 2011; Toews and Allen 2009; Kurylyk and MacQuarrie 2013). The authors fully agree with this recommendation, but believe that the adopted approach is incomplete. As was demonstrated, different model concepts and associated complexities lead (not surprisingly) to different results. It is therefore recommended that ensembles of climate projections should be coupled with ensembles of hydrogeological models to produce credible predictions of future recharge and the associated uncertainties. Although the proposed approach is certainly computationally demanding and more efficient methods to simulate the effect of climate change on recharge are desired, the proposed holistic approach will provide a more realistic representation of future uncertainty in recharge estimations.

Acknowledgements The authors gratefully acknowledge the financial assistance provided by the Swiss National Science Foundation, Project NFP 61, Sustainable Water Management. We are grateful for the valuable feedback by the editor, reviewer Sergey Grinevskii and the anonymous reviewer. We thank John Molson and Anja Bretzler for their assistance with the manuscript. The $\mathrm{CH} 2011$ data were obtained from the Center for Climate Systems Modeling (C2SM).

\section{References}

Aeschbach-Hertig W, Gleeson T (2012) Regional strategies for the accelerating global problem of groundwater depletion. Nat Geosci 5:853-861

Allen DM, Mackie DC, Wei M (2004) Groundwater and climate change: a sensitivity analysis for the Grand Forks aquifer, southern British Columbia, Canada. Hydrogeol J 12:270-290. doi:10.1007/s10040003-0261-9

Allen RG, Pereira LS, Smith M, Raes D, Wright JL (2005) FAO-56 dual crop coefficient method for estimating evaporation from soil and application extensions. J Irrig Drain E-ASCE 131(1)2-13. doi:10. 1061/(Asce)0733-9437(2005)131:1(2)

Bakker M, Bartholomeus RP, Ferre TPA (2013) Preface "Groundwater recharge: processes and quantification". Hydrol Earth Syst Sci 17: 2653-2655. doi:10.5194/hess-17-2653-2013

Bastola S, Murphy C, Sweeney J (2011) The role of hydrological modelling uncertainties in climate change impact assessments of Irish river catchments. Adv Water Resour 34:562-576

Bennett ND, Croke BFW, Guariso G, Guillaume JHA, Hamilton SH, Jakeman AJ, Marsili-Libelli S, Newham LTH, Norton JP, Perrin C, Pierce SA, Robson B, Seppelt R, Voinov AA, Fath BD, Andreassian V (2013) Characterising performance of environmental models. Environ Modell Softw 40:1-20. doi:10.16/j.envsoft.2012. 09.011

Bosshard T, Kotlarski S, Ewen T, Schar C (2011) Spectral representation of the annual cycle in the climate change signal. Hydrol Earth Syst Sci 15:2777-2788. doi:10.5194/hess-15-2777-2011
Brigode P, Oudin L, Perrin C (2013) Hydrological model parameter instability: a source of additional uncertainty in estimating the hydrological impacts of climate change? J Hydrol 476:410-425

Brouyere S, Carabin G, Dassargues A (2004) Climate change impacts on groundwater resources: modelled deficits in a chalky aquifer, Geer basin, Belgium. Hydrogeol J 12:123-134. doi:10.1007/s10040-0030293-1

Brunner P, Simmons CT (2012) HydroGeoSphere: a fully integrated, physically based hydrological model. Ground Water 50:170-176. doi:10.1111/j.1745-6584.2011.00882.x

Carsel RF, Parrish RS (1988) Developing joint probability distributions of soil-water retention characteristics. Water Resour Res 24:755-769. doi:10.1029/Wr024i005p00755

CH2011 (2011) Swiss climate change scenarios 2011. C2SM MeteoSwiss, ETH, NCCR Climate, and OcC, Zurich, Switzerland, $88 \mathrm{pp}$

Coron L, Andreassian V, Perrin C, Lerat J, Vaze J, Bourqui M, Hendrickx F (2012) Crash testing hydrological models in contrasted climate conditions: an experiment on 216 Australian catchments. Water Resour Res 48, W05552 doi:10.1029/2011wr011721

Crosbie RS, Dawes WR, Charles SP, Mpelasoka FS, Aryal S, Barron O, Summerell GK (2011) Differences in future recharge estimates due to GCMs, downscaling methods and hydrological models. Geophys Res Lett 38, L11406. doi:10.1029/2011g1047657

Cuthbert MO, Tindimugaya C (2010) The importance of preferential flow in controlling groundwater recharge in tropical Africa and implications for modelling the impact of climate change on groundwater resources. J Water Clim Change 1:234-245. doi:10.2166/ Wcc. 2010.040

Doherty JE (2011) PEST: model-independent parameter estimation. User manual. Watermark, Brisbane, Australia. Available at http://www. pesthomepage.org/Downloads.php. Accessed 29 May 2015

Döll P, Fiedler K (2008) Global-scale modeling of groundwater recharge. Hydrol Earth Syst Sci 12:863-885

Droogers P, Van Loon A, Immerzeel WW (2008) Quantifying the impact of model inaccuracy in climate change impact assessment studies using an agro-hydrological model. Hydrol Earth Syst Sci 12: 669-678

Ferguson IM, Maxwell RM (2010) Role of groundwater in watershed response and land surface feedbacks under climate change. Water Resour Res 46, W00f02. doi:10.1029/2009wr008616

Finch JW (1998) Estimating direct groundwater recharge using a simple water balance model: sensitivity to land surface parameters. J Hydrol 211:112-125. doi:10.1016/S0022-1694(98)00225-X

Finch JW (2001) Estimating change in direct groundwater recharge using a spatially distributed soil water balance model. Quart J Eng Geol Hydrogeol 34:71-83

Ghasemizade M, Moeck C, Schirmer M (2015) The effect of model complexity in simulating unsaturated zone flow processes on recharge estimation at varying time scales. J Hydrol 529:3-1173. doi:10.1016/j.jhydrol.2015.09.027

Goderniaux P, Brouyere S, Blenkinsop S, Burton A, Fowler HJ, Orban P, Dassargues A (2011) Modeling climate change impacts on groundwater resources using transient stochastic climatic scenarios. Water Resour Res 47, W12516. doi:10.1029/2010wr010082

Goderniaux P, Brouyere S, Fowler HJ, Blenkinsop S, Therrien R, Orban P, Dassargues A (2009) Large scale surface-subsurface hydrological model to assess climate change impacts on groundwater reserves. J Hydrol 373:122-138. doi:10.1016/j.jhydrol.2009.04.017

Goderniaux $\mathrm{P}$, Brouyère $\mathrm{S}$, Wildemeersch $\mathrm{S}$, Therrien R, Dassargues A (2015) Uncertainty of climate change impact on groundwater reserves: application to a chalk aquifer. J Hydrol 528:108-121. doi: 10.1016/j.jhydrol.2015.06.018

Green TR, Taniguchi M, Kooi H, Gurdak JJ, Allen DM, Hiscock KM, Treidel H, Aureli A (2011) Beneath the surface of global change: impacts of climate change on groundwater. J Hydrol 405:532-560 
Gupta HV, Sorooshian S, Yapo PO (1999) Status of automatic calibration for hydrologic models: comparison with multilevel expert calibration. J Hydrol Eng 4:135-143. doi:10.1061/(Asce)1084-0699(1999) 4:2(135)

Hartmann A, Lange J, Aguado AV, Mizyed N, Smiatek G, Kunstmann H (2012) A multi-model approach for improved simulations of future water availability at a large Eastern Mediterranean karst spring. J Hydrol 468:130-138

Holman IP (2006) Climate change impacts on groundwater recharge: uncertainty, shortcomings, and the way forward? Hydrogeol J 4: 637-647. doi:10.1007/s10040-005-0467-0

Jiang T, Chen YD, Xu C-y, Chen X, Chen X, Singh VP (2007) Comparison of hydrological impacts of climate change simulated by six hydrological models in the Dongjiang Basin South China. J Hydrol 336:316-333. doi:10.1016/j.jhydrol.2007.01.010

Jyrkama MI, Sykes JF (2007) The impact of climate change on spatially varying groundwater recharge in the Grand River watershed (Ontario). J Hydrol 338:237-250. doi:10.1016/j.jhydrol.2007. 02.036

Kim JH, Jackson RB (2012) A global analysis of groundwater recharge for vegetation, climate, and soils. Vadose Zone J 11

Kingston DG, Taylor RG (2010) Sources of uncertainty in climate change impacts on river discharge and groundwater in a headwater catchment of the Upper Nile Basin, Uganda. Hydrol Earth Syst Sci 14: 1297-1308. doi:10.5194/hess-14-1297-2010

Kinzelbach W, Bauer P, Siegfried T, Brunner P (2003) Sustainable groundwater management: problems and scientific tools. Episodes 26:279-284

Krause P, Boyle DP, Bäse F (2005) Comparison of different efficiency criteria for hydrological model assessment. Adv Geosci 5:89-97. doi:10.5194/adgeo-5-89-2005

Kresic N (2006) Hydrogeology and groundwater modeling. CRC, Boca Raton, FL

Kristensen KJ, Jensen SE (1975) A model of estimating actual evapotranspiration from potential evapotranspiration. Nordic Hydrol 6: 170-188

Kurylyk BL, MacQuarrie KTB (2013) The uncertainty associated with estimating future groundwater recharge: a summary of recent research and an example from a small unconfined aquifer in a northern humid-continental climate. J Hydrol 492:244-253. doi:10.1016/j. jhydrol.2013.03.043

Leterme B, Mallants D, Jacques D (2012) Sensitivity of groundwater recharge using climatic analogues and HYDRUS-1D. Hydrol Earth Syst Sci 16:2485-2497. doi:10.5194/hess-16-2485-2012

Lorenz DL, Delin GN (2007) A regression model to estimate regional ground water recharge. Ground Water 45:196-208

Merz R, Parajka J, Bloschl G (2011) Time stability of catchment model parameters: implications for climate impact analyses. Water Resour Res 47(2), W02531

Mileham L, Taylor R, Thompson J, Todd M, Tindimugaya C (2008) Impact of rainfall distribution on the parameterisation of a soilmoisture balance model of groundwater recharge in equatorial Africa. J Hydrol 359:46-58. doi:10.1016/j.jhydrol.2008.06.007

Mileham L, Taylor RG, Todd M, Tindimugaya C, Thompson J (2009) The impact of climate change on groundwater recharge and runoff in a humid, equatorial catchment: sensitivity of projections to rainfall intensity. Hydrol Sci J 54:727-38. doi:10.1623/hysj.54.4.727

Moeck C, Hunkeler D, Brunner P (2015) Tutorials as a flexible alternative to GUIs: An example for advanced model calibration using Pilot Points. Environ Modell Softw 66:78-86

Nash JE, Sutcliffe JV (1970) River flow forecasting through conceptual models, part I: a discussion of principles. J Hydrol 10:282-290. doi: 10.1016/0022-1694(70)90255-6

Newcomer ME, Gurdak JJ, Sklar LS, Nanus L (2014) Urban recharge beneath low impact development and effects of climate variability and change. Water Resour Res 50:1716-1734
Owor M, Taylor RG, Tindimugaya C, Mwesigwa D (2009) Rainfall intensity and groundwater recharge: empirical evidence from the Upper Nile Basin. Environ Res Lett 4(3)

Petheram C, Walker G, Grayson R, Thierfelder T, Zhang L (2002) Towards a framework for predicting impacts of land-use on recharge: 1. a review of recharge studies in Australia. Aust J Soil Res 40:397-417

Pulido-Velazquez D, Garcia-Arostegui JL, Molina JL, Pulido-Velazquez M (2015) Assessment of future groundwater recharge in semi-arid regions under climate change scenarios (Serral-Salinas aquifer, SE Spain). Could increased rainfall variability increase the recharge rate? Hydrol Process 29:828-844

Richter W, Lillich W (1975) Abriss der Hydrogeologie [Introduction to hydrogeology]. Schweizerbart'sche, Stuttgart, Germany, $281 \mathrm{pp}$

Rossman NR, Zlotnik VA, Rowe CM, Szilagyi J (2014) Vadose zone lag time and potential 21 st century climate change effects on spatially distributed groundwater recharge in the semi-arid Nebraska Sand Hills. J Hydrol 519:656-669

Schaap MG, Leij FJ, van Genuchten MT (2001) ROSETTA: a computer program for estimating soil hydraulic parameters with hierarchical pedotransfer functions. J Hydrol 251:163-176. doi:10.1016/S00221694(01)00466-8

Schar C, Jendritzky G (2004) Climate change: Hot news from summer 2003. Nature 432:559-560. doi:10.1038/432559a

Schluter S, Vanderborght J, Vogel HJ (2012) Hydraulic non-equilibrium during infiltration induced by structural connectivity. Adv Water Resour 44:101-112. doi:10.1016/j.advwatres.2012.05.002

Scibek J, Allen DM (2006a) Comparing modelled responses of two highpermeability, unconfined aquifers to predicted climate change. Global Planet Change 50:50-62. doi:10.1016/j.gloplacha. 2005.10.002

Scibek J, Allen DM (2006b) Modeled impacts of predicted climate change on recharge and groundwater levels. Water Resour Res 42 , W11405. doi: 10.1029/2005wr004742

Seiller G, Anctil F, Perrin C (2012) Multimodel evaluation of twenty lumped hydrological models under contrasted climate conditions. Hydrol Earth Syst Sci 16:1171-1189. doi:10.5194/hess-161171-2012

Seneviratne SI, Lehner I, Gurtz J, Teuling AJ, Lang H, Moser U, Grebner D, Menzel L, Schroff K, Vitvar T, Zappa M (2012) Swiss prealpine Rietholzbach research catchment and lysimeter: 32 year time series and 2003 drought event. Water Resour Res 48, W06526. doi:10. 1029/2011wr011749

Serrat-Capdevila A, Valdes JB, Perez JG, Baird K, Mata LJ, Maddock T (2007) Modeling climate change impacts and uncertainty on the hydrology of a riparian system: The San Pedro Basin (Arizona/Sonora). J Hydrol 347:48-66. doi:10. 1016/j.jhydrot.2007.08.028

Shah N, Nachabe M, Ross M (2007) Extinction depth and evapotranspiration from ground water under selected land covers. Ground Water 45:329-338. doi:10.1111/j.1745-6584.2007.00302.x

Shamir E, Megdal SB, Carrillo C, Castro CL, Chang HI, Chief K, Corkhill FE, Eden S, Georgakakos KP, Nelson KM, Prietto J (2015) Climate change and water resources management in the Upper Santa Cruz River, Arizona. J Hydrol 521:18-33

Sorensen JPR, Finch JW, Ireson AM, Jackson CR (2014) Comparison of varied complexity models simulating recharge at the field scale. Hydrol Process 28:2091-2102. doi:10.1002/Hyp.9752

Staudinger M, Weiler M, Seibert J (2015) Quantifying sensitivity to droughts: an experimental modeling approach. Hydrol Earth Syst Sci 19:1371-1384

Stoll S, Franssen HJH, Barthel R, Kinzelbach W (2011) What can we learn from long-term groundwater data to improve climate change impact studies? Hydrol Earth Syst Sci 15:3861-3875. doi:10.5194/ hess-15-3861-2011 
Sulis M, Paniconi C, Rivard C, Harvey R, Chaumont D (2011) Assessment of climate change impacts at the catchment scale with a detailed hydrological model of surface-subsurface interactions and comparison with a land surface model. Water Resour Res 47, W01513. doi:10.1029/2010wr009167

Sulis M, Paniconi C, Marrocu M, Huard D, Chaumont D (2012) Hydrologic response to multimodel climate output using a physically based model of groundwater/surface water interactions. Water Resour Res 48, W12510. doi:10.1029/2012wr012304

Teutschbein C, Seibert J (2012) Bias correction of regional climate model simulations for hydrological climate-change impact studies: review and evaluation of different methods. J Hydrol 456-457:12-29 doi: 10.1016/j.jhydrol.2012.05.052

Teng J, Vaze J, Chiew FHS, Wang B, Perraud JM (2012) Estimating the relative uncertainties sourced from GCMs and hydrological models in modeling climate change impact on runoff. J Hydrometeorol 13: 122-139

Therrien R, McLaren RG, Sudicky EA (2010) HydroGeoSphre: a three dimensional numerical model describing fully integrated subsurface and surface flow and solute transport. Groundwater Simulations Group, University of Waterloo, Waterloo, ON

Toews MW, Allen DM (2009) Evaluating different GCMs for predicting spatial recharge in an irrigated arid region. J Hydrol 374: 265-281. doi:10.1016/j.jhydrol.2009.06.022

Van Genuchten MT (1980) A closed-form equation for predicting the hydraulic conductivity of unsaturated soils. Soil Sci Soc Am J 44: 892-898

van Roosmalen L, Sonnenborg TO, Jensen KH (2009) Impact of climate and land use change on the hydrology of a large-scale agricultural catchment. Water Resour Res 45, W00a15. doi:10.1029/ 2007wr006760

van Vuuren D, Edmonds J, Kainuma M, Riahi K, Thomson A, Hibbard K, Hurtt G, Kram T, Krey V, Lamarque J-F, Masui T, Meinshausen M, Nakicenovic N, Smith S, Rose S (2011) The representative concentration pathways: an overview. Climatic Change 109:5-31. doi: 10.1007/s10584-011-0148-z

Vaze J, Post DA, Chiew FHS, Perraud JM, Viney NR, Teng J (2010) Climate non-stationarity: validity of calibrated rainfallrunoff models for use in climate change studies. J Hydrol 394:447-457

Vogel H-J, Ippisch O (2008) Estimation of a critical spatial discretization limit for solving Richards' equation at large scales. Vadose Zone J 7: 112-114. doi:10.2136/vzj2006.0182

von Freyberg J, Moeck C, Schirmer M (2015) Estimation of groundwater recharge and drought severity with varying model complexity. J Hydrol 527:844-857. doi:10.1016/j.jhydrol.2015.05.025

Watson TA, Doherty JE, Christensen S (2013) Parameter and predictive outcomes of model simplification. Water Resour Res 49:39523977. doi:10.1002/Wrcr.20145

Wohling DL, Leaney FW, Crosbie RS (2012) Deep drainage estimates using multiple linear regression with percent clay content and rainfall. Hydrol Earth Syst Sci 16:563-572

Woldeamlak ST, Batelaan O, De Smedt F (2007) Effects of climate change on the groundwater system in the Grote-Nete catchment, Belgium. Hydrogeol J 15:891-901. doi:10.1007/s10040-0060145-x

Zhang Y, Wang JC, Jing JH, Sun JC (2014) Response of groundwater to climate change under extreme climate conditions in North China Plain. J Earth Sci-China 25:612-618 